\title{
Midterm outcomes and predictors of reintervention after the Ross procedure in infants, children, and young adults
}

Sara K. Pasquali, MD, ${ }^{a}$ David Shera, $S c D,{ }^{b}$ Gil Wernovsky, MD, ${ }^{a}$ Meryl S. Cohen, MD, ${ }^{a}$ Sarah Tabbutt, MD, PhD, a,c Susan Nicolson, MD, ${ }^{d}$ Thomas L. Spray, MD, ${ }^{e}$ and Bradley S. Marino, MD, MPP, MSCE ${ }^{a, c}$

From the Divisions of Cardiology, ${ }^{\mathrm{a}}$ Biostatistics and Epidemiology, ${ }^{\mathrm{b}}$ Critical Care Medicine, ${ }^{\mathrm{c}}$ Anesthesia, ${ }^{\mathrm{d}}$ and Cardiothoracic Surgery ${ }^{\mathrm{e}}$ in the Departments of Pediatrics, Surgery, and Anesthesia/Critical Care Medicine at The Children's Hospital of Philadelphia, University of Pennsylvania School of Medicine, Philadelphia, Pa.

Presented at the American Academy of Pediatrics Section on Cardiology and Cardiac Surgery 2005 Scientific Session. Dr Pasquali was a Young Investigator Award recipient.

Received for publication July 13, 2006; revisions received Oct 3, 2006; accepted for publication Dec 18, 2006.

Address for reprints: Bradley S. Marino, MD, MPP, MSCE, Assistant Professor of Anesthesia and Pediatrics, University of Pennsylvania School of Medicine, The Children's Hospital of Philadelphia, 7th Floor Main, 34th St. and Civic Center Boulevard, Philadelphia, PA 19104 (E-mail: marino@email.chop.edu).

J Thorac Cardiovasc Surg 2007;133:893-9

$0022-5223 / \$ 32.00$

Copyright $(92007$ by The American Association for Thoracic Surgery

doi:10.1016/j.jtcvs.2006.12.006
Objectives: This study assessed the type, time course, and risk factors for right and left ventricular outflow tract reinterventions after the Ross procedure in a population of infants, children, and young adults.

Methods: Patients who underwent the Ross procedure between January 1995 and June 2004 were included ( $\mathrm{n}=121$ consecutive patients). Kaplan-Meier and hazard analyses of right and left ventricular outflow tract reinterventions were performed, and predictors of reintervention were identified through multivariate analysis.

Results: The median age at the Ross procedure was 8.2 years (4 days to 34 years); $20 \%$ were aged less than 1 year. Half of the patients had isolated aortic valve disease; the other half had complex left-sided heart disease. Early mortality $(<30$ days) was $2.5 \%(\mathrm{n}=3)$. There were 2 late deaths $(1.7 \%)$. Follow-up (median 6.5 years [2.5 months to 10.4 years]) was available for $96 \%$ of survivors $(n=111)$. Right ventricular outflow tract reintervention ( $\mathrm{n}=22$ in 15 patients) was performed 2.0 years (2.0 weeks to 9.8 years) after the Ross procedure because of stenosis in 19 of 22 cases. Freedom from right ventricular outflow tract reintervention at 8 years was $81 \%$. Smaller homograft size was the strongest predictor $(P<.001)$ of right ventricular outflow tract reintervention. Left ventricular outflow tract reintervention $(\mathrm{n}=15$ in 15 patients) was performed 2.8 years ( 1.0 months to 11.6 years) after the Ross procedure because of severe neoaortic insufficiency in 10 of 15 patients. Freedom from left ventricular outflow tract reintervention at 8 years was $83 \%$. Native pulmonary valve abnormalities $(P<.01)$, original diagnosis of aortic insufficiency $(P<.01)$, prior aortic valve replacement $(P=.01)$, and prior ventricular septal defect repair $(P=.04)$ predicted left ventricular outflow tract reintervention.

Conclusions: At midterm follow-up after the Ross procedure, interim mortality is rare. Neoaortic insufficiency and right ventricle to pulmonary artery conduit obstruction are common postoperative sequelae, requiring reintervention in one quarter of patients.

$\mathrm{T}$ The Ross procedure, first described in 1967, is an attractive option in the treatment of aortic valve disease in infants, children, and young adults. ${ }^{1}$ In comparison with mechanical and homograft valves, anticoagulation is not required and the pulmonary autograft is capable of growth. ${ }^{1-3}$ The Ross procedure has been performed with low mortality in children and adolescents with isolated aortic valve disease, and in infants and those with complex left ventricular outflow tract (LVOT) obstruction. ${ }^{3-11}$ Long-term outcomes after the Ross procedure remain uncertain. Although the pulmonary autograft is capable of growth, the pulmonary homograft placed in the right ventricular outflow tract (RVOT) does not grow; thus, reintervention can be expected in some patients. ${ }^{12-14}$ In addition, the development of neoaortic insufficiency and neoaortic root dilation out of proportion to somatic 


\section{Abbreviations and Acronyms}

LVOT $=$ left ventricular outflow tract

$\mathrm{RVOT}=$ right ventricular outflow tract

VSD $=$ ventricular septal defect

growth after the Ross procedure may necessitate LVOT reintervention. ${ }^{13-17}$ Although RVOT and LVOT reinterventions have been shown to occur, the timing and predictors of reintervention have not been well described in the pediatric population who have undergone the Ross procedure. This study evaluated the midterm outcomes after the Ross procedure, including the type, time course, and predictors of RVOT and LVOT reinterventions in a large population of infants, children, and young adults.

\section{Materials and Methods}

Study Design and Patient Population

This study was approved by our institutional review board. It is a cross-sectional analysis of a consecutive series of patients who underwent the Ross procedure at the Children's Hospital of Philadelphia in isolation, or in combination with other procedures, between January 1995 and June 2004. Patients who died were excluded from further analysis.

\section{Data Collection}

Charts were reviewed for age at surgery, sex, original anatomic diagnoses, prior interventions, indication for the Ross procedure, postoperative complications, and mortality. Patients were defined as having "isolated" aortic valve disease if they had aortic stenosis, aortic insufficiency, or both, with no other significant left-sided heart disease present. Patients were defined as having "complex" left-sided heart disease if they had multiple levels of left-sided heart obstruction or additional hemodynamic or structural abnormalities that required surgical intervention. Information on additional procedures performed and the duration of cardiopulmonary bypass, myocardial ischemia, and circulatory arrest was obtained from the operative record. Follow-up data, including RVOT or LVOT reintervention (surgical or catheter-related procedures), were obtained from clinic charts or cardiac databases for patients followed by our institution, as well as those followed by outside cardiologists.

Echocardiographic data, including shortening fraction, left ventricular dimensions, and degree of neoaortic and pulmonary stenosis or insufficiency, before the Ross procedure and at follow-up were obtained from the echocardiographic database at our institution or from echocardiographic reports for those patients followed by outside cardiologists.

\section{Statistical Analysis}

A cross-sectional analysis of known survivors was performed in August 2005. Summary statistics are expressed as means and standard deviation, or medians and ranges where appropriate. Kaplan-Meier and Cox hazard analyses of RVOT and LVOT reinterventions were performed. On the basis of this analysis,
TABLE 1. Population characteristics

\begin{tabular}{lc}
\hline & (n = 121) \\
\hline Median age at Ross & 8.2 y (4 d to 34 y) \\
$\quad<1$ y & $20(24 \%)$ \\
Sex, male & $82(68 \%)$ \\
Isolated aortic valve disease vs complex & $60(50 \%)$ \\
$\quad$ left-sided heart disease & \\
Patients with procedures before Ross & $91(75 \%)$ \\
Indication for Ross: & \\
Combined AS/AI & $77(64 \%)$ \\
AS & $24(20 \%)$ \\
Al & $20(16 \%)$ \\
Concurrent procedures with Ross & $75(62 \%)$
\end{tabular}

$A S$, Aortic stenosis; $A l$, aortic insufficiency.

RVOT and LVOT reinterventions were characterized as occurring in the "early" ( $<4$ years post-Ross) or "late" ( $>4$ years post-Ross) time period. Predictors of RVOT and LVOT reinterventions were identified through univariate analysis and Cox proportional hazards regression analysis. A 2-sample test of proportions and paired $t$ test were used to assess the differences in left ventricular size before and after the Ross procedure.

\section{Results \\ Population Characteristics}

A total of 121 patients met inclusion criteria. Patient demographics are shown in Table 1. Of note, our study population included a significant number of neonates and infants (20\% aged $<1$ year at the time of the Ross procedure) and patients with complex left-sided heart disease $(n=60$, $50 \%$ ). The Ross procedure was the first intervention in a minority of patients $(\mathrm{n}=30,25 \%)$. Table 2 displays the 229

\section{TABLE 2. Procedures before the Ross operation}

\begin{tabular}{lc}
\hline Isolated disease & $\mathrm{N}=71$ (43 pts) \\
Balloon valvotomy & 21 \\
Surgical valvotomy & 19 \\
Surgical valvuloplasty & 13 \\
VSD repair & 5 \\
Aortic valve replacement & 4 \\
Other & 9 \\
Complex disease & 158 (48 patients) \\
Balloon valvotomy & 30 \\
Coarctation repair/dilation & 27 \\
Sub-AS resection/Konno & 19 \\
Surgical valvotomy & 16 \\
VSD repair & 14 \\
Interrupted aortic arch repair & 6 \\
Apical aortic conduit & 3 \\
Mitral valvuloplasty & 2 \\
Other & 31
\end{tabular}

$V S D$, ventricular septal defect; $A S$, aortic stenosis. 


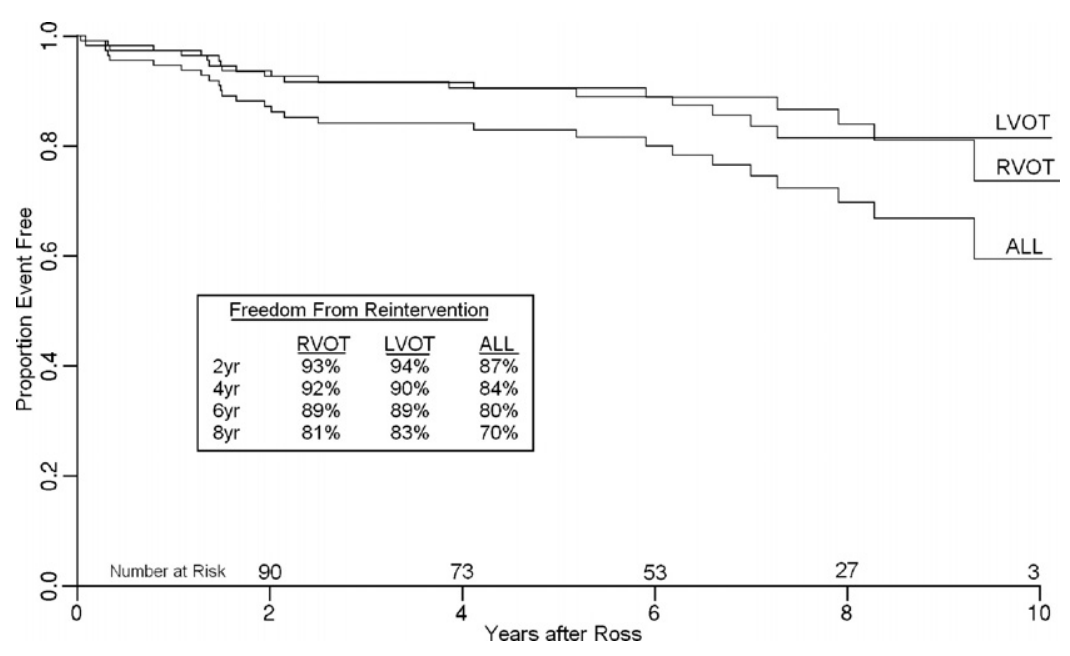

Figure 1. Kaplan-Meier estimates of freedom from RVOT and LVOT reinterventions after the Ross procedure. RVOT, Right ventricular outflow tract; $L$ VOT, left ventricular outflow tract.

procedures performed before the Ross operation. The most common prior procedure was balloon valvotomy in 51 patients $(42 \%)$.

\section{Surgical Indications and Technique}

The indication for the Ross procedure was a combination of aortic stenosis and insufficiency in the majority of patients ( $\mathrm{n}=77,64 \%$; Table 1). The Ross procedure, as previously described, was performed along with a total of 150 concurrent procedures in 75 patients $(62 \%) .{ }^{18}$ Of the 60 patients with isolated aortic valve disease, 12 (20\%) required a concurrent aortic annulus enlargement procedure (an incision made in the aortic wall in the region of the noncoronary cusp of the aortic valve and carried down across the aortic valve annulus) because of a minor size discrepancy between the native aortic and pulmonary valves. All but 2 of the patients with complex left-sided heart disease underwent additional procedures at the time of the Ross operation. A concurrent Konno procedure (an incision made between the commissures of the right and left coronary cusps of the aortic valve and carried across the aortic valve annulus into the ventricular septum) was performed in 49 of the 61 patients $(80 \%)$ because of a significant size discrepancy between the native aortic and pulmonary valves. Other concurrent procedures in patients with complex leftsided heart disease included mitral valve replacement or repair (14), subaortic membrane resection (14), arch augmentation (11), ventricular septal defect (VSD) repair (6), apical aortic conduit division (3), and aortic annulus enlargement (3).

At the time of the Ross procedure, a valved pulmonary homograft was used in 113 patients (93\%) to reconstruct the RVOT. In the other 8 patients, an aortic homograft was used. The median homograft size was $23 \mathrm{~mm}$ (range 10-29 mm).

\section{Mortality}

Early mortality ( $<30$ days) was $2.5 \%(\mathrm{n}=3)$. Two patients with complex disease died in the hospital; 1 patient had severe postoperative ventricular dysfunction, and the other had ventricular tachycardia and cardiac arrest. The third patient had isolated aortic valve disease and died soon after hospital discharge. Dehiscence of the neoaortic root was identified at autopsy.

There were 2 late deaths $(1.7 \%)$. Both patients had complex left-sided heart disease with left ventricular and/or mitral valve hypoplasia resulting in pulmonary hypertension and severe right ventricular dysfunction.

\section{Follow-up and Reintervention}

Follow-up information was available in 111 of 116 survivors $(96 \%)$. The median follow-up was 6.5 years $(2.5$ months to 10.4 years), or 685 patient-years. A total of 27 of 111 survivors $(25 \%)$ underwent reintervention related to the Ross procedure; 12 patients (11\%) underwent RVOT reintervention, 12 patients (11\%) underwent LVOT reintervention, and 3 patients $(3 \%)$ underwent both. There were also 8 patients $(7 \%)$ who underwent 10 "other" reinterventions (recoarctation balloon dilation $[\mathrm{n}=4]$, mitral valve replacement $[\mathrm{n}=2]$, mitral valvuloplasty $[\mathrm{n}=1]$, VSD closure $[\mathrm{n}=1]$, atrial septal defect device closure $[\mathrm{n}=1]$, and supravalvar aortic stenosis repair distal to the sight of the anastomosis of the pulmonary autograft $[n=1])$. Four of these "other" reinterventions were in 3 patients who had also had Ross-related reintervention.

\section{Right Ventricular Outflow Tract Reintervention}

The Kaplan-Meier curve for RVOT reintervention is shown in Figure 1. Freedom from RVOT reintervention 8 years after the Ross procedure was $81 \%$. There seemed to be an early ( $<4$ years post-Ross) and late $(>4$ years post-Ross) 


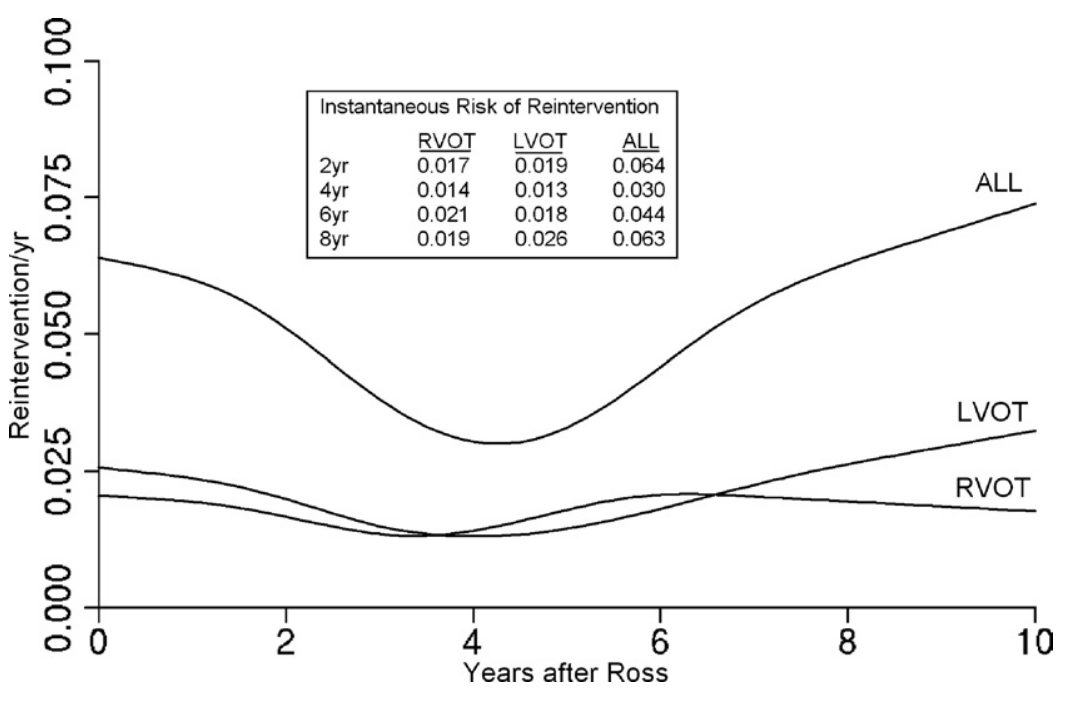

Figure 2. Hazard analysis of instantaneous risk of reintervention after the Ross procedure. RVOT, Right ventricular outflow tract; $L V O T$, left ventricular outflow tract.

period of RVOT reintervention, which is also demonstrated by the hazard curve (Figure 2).

The details of RVOT reintervention during both the "early" and "late" time periods after the Ross procedure are shown in Table 3. Twenty-two RVOT reinterventions were performed in 15 patients ( 3 patients had multiple procedures) at a median of 2.0 years ( 2.0 weeks to 9.8 years) after the Ross procedure. Fourteen of the procedures were surgical, and 8 were catheter-directed therapies. In 19 of 22 cases, reintervention was required because of significant stenosis, either of the conduit or the anastomosis between the conduit and the right pulmonary artery. The mean conduit gradient at reintervention was $63 \pm 15 \mathrm{~mm} \mathrm{Hg}$. Two patients underwent upsizing of their conduit at the time of LVOT reintervention, and 1 patient underwent conduit replacement because of pseudoaneurysm formation at the proximal end of the conduit.

Three patients underwent multiple procedures. One patient had a right pulmonary artery stent placed that was subsequently balloon dilated on 3 separate occasions. One patient underwent conduit and right pulmonary artery balloon dilation, followed by conduit replacement. The third patient underwent conduit replacement, followed by conduit balloon dilation, and then a second conduit replacement.

Predictors of RVOT reintervention are displayed in Table 4 . In multivariate analysis, smaller homograft size $(P=$ $.0002)$ and longer cardiopulmonary bypass time $(P=.009)$ were significant predictors of RVOT reintervention after the Ross procedure. As expected, younger age and smaller homograft size were highly correlated.

\section{Left Ventricular Outflow Tract Reintervention}

The Kaplan-Meier Curve for LVOT reintervention is shown in Figure 1. The curve for LVOT reintervention parallels that of RVOT reintervention, with freedom from LVOT reintervention 8 years after the Ross procedure of $83 \%$. As with RVOT reintervention, there seems to be an "early" $(<4$ years post-Ross) and "late" ( $>4$ years post-Ross) phase of LVOT reintervention (Figures 1 and 2).

The details of LVOT reintervention during both the "early" and "late" time periods are displayed in Table 3. Fifteen reinterventions were performed in 15 patients at a median of 2.8 years (range 1.0 months to 11.6 years) after the Ross procedure. The majority $(n=10)$ of the reinterventions were required because of severe neoaortic insufficiency. Three other patients had progressive neoaortic root dilation (mean neoaortic sinus $z$ score $5.7 \pm 0.7$ at the time of reintervention) and underwent valve sparing root replacement. Two patients underwent neoaortic aneurysm repair after the Ross procedure: One patient had a recurrent episode of endocarditis and an aneurysm developed at the proximal suture line of the pulmonary autograft, and 1 patient had a pseudoaneurysm at the proximal suture line of the pulmonary autograft.

The predictors of LVOT reintervention are displayed in Table 4. In multivariate analysis, the presence of native pulmonary valve abnormalities, such as a discrepancy in leaflet size, bicuspid pulmonary valve or pulmonary valve annulus abnormalities secondary to prior VSD repair $(P=$ $.005)$, original diagnosis of aortic insufficiency $(P=.006)$, aortic valve replacement before the Ross procedure $(P=$ $.01)$, VSD repair before the Ross procedure $(P=.04)$, and longer cardiopulmonary bypass time during the Ross procedure $(P=.003)$, were significant predictors of LVOT reintervention.

\section{Echocardiographic Data}

Excluding those who had LVOT reintervention, there were 13 patients (14\%) with moderate neoaortic insufficiency at midterm follow-up. No patient had severe neoaortic insuf- 
TABLE 3. Reintervention

\begin{tabular}{|c|c|c|}
\hline \multicolumn{3}{|l|}{ RVOT } \\
\hline \multirow[b]{2}{*}{ Cause } & \multicolumn{2}{|c|}{$\mathbf{N}=22$ (15 patients) } \\
\hline & Early & Late \\
\hline \multicolumn{3}{|l|}{ Conduit stenosis } \\
\hline Replacement & 6 & 3 \\
\hline Augmentation & 2 & \\
\hline Balloon dilation & 1 & 1 \\
\hline Stent & 1 & \\
\hline Conduit upsizing & & 2 \\
\hline \multicolumn{3}{|l|}{ Conduit pseudoaneurysm } \\
\hline Replacement & 1 & \\
\hline \multicolumn{3}{|l|}{ RPA stenosis } \\
\hline Balloon dilation & 4 & \\
\hline Stent & 1 & \\
\hline \multicolumn{3}{|l|}{ LVOT } \\
\hline & \multicolumn{2}{|c|}{$N=15$ (15 patients) } \\
\hline Cause & Early & Late \\
\hline \multicolumn{3}{|l|}{ Severe neo-Al } \\
\hline $\begin{array}{l}\text { St Jude AVR (St Jude Medical, } \\
\text { St Paul, Minn) }\end{array}$ & 5 & 2 \\
\hline Homograft AVR & 2 & \\
\hline Valvuloplasty & 1 & \\
\hline \multicolumn{3}{|l|}{ Neoaortic root dilation } \\
\hline Root replacement & & 3 \\
\hline \multicolumn{3}{|l|}{ Neoaortic root aneurysm } \\
\hline Aneurysm repair & & 2 \\
\hline
\end{tabular}

RPA, Right pulmonary artery; $A V R$, aortic valve replacement; $A l$, aortic insufficiency; RVOT, right ventricular outflow tract; $L V O T$, left ventricular outflow tract.

ficiency. There were 6 patients $(6 \%)$ with LVOT obstruction; the mean gradient was $15 \pm 3 \mathrm{~mm} \mathrm{Hg}$. Excluding those who had undergone RVOT reintervention, there were 17 patients with moderate pulmonary insufficiency and 11 patients with severe pulmonary insufficiency $(\mathrm{n}=28$, $28 \%)$. Fifty-six patients (58\%) had RVOT obstruction, with a mean gradient of $32 \pm 14 \mathrm{~mm} \mathrm{Hg}$.

Complete echocardiographic data on left ventricular size and function before the Ross procedure and at follow-up were available in 78 of 111 survivors $(70 \%)$. Shortening fraction was similar before and after the Ross procedure $(39 \% \pm 10 \%$ vs $36 \% \pm 7 \%)$. There was also no difference in the proportion of patients with a shortening fraction less than $28 \%$ before and after the Ross procedure (9\% vs $8 \%$ ).

Before the Ross procedure, the mean left ventricular end-diastolic dimension was $4.7 \pm 1.6 \mathrm{~cm}$ with a mean $z$ score of $1.3 \pm 1.5$. The proportion of patients with a left ventricular end-diastolic dimension $z$ score greater than 2 was $36 \%$. At follow-up, left ventricular end-diastolic dimension was similar $(4.8 \pm 0.9 \mathrm{~cm})$. However, the mean left ventricular end-diastolic dimension $z$ score $(0.7 \pm 1.0)$
TABLE 4. Predictors of reintervention

\begin{tabular}{|c|c|c|}
\hline & \multicolumn{2}{|c|}{$P$ values } \\
\hline & Univariate & Multivariate \\
\hline \multicolumn{3}{|l|}{ RVOT } \\
\hline Smaller homograft size & $<.0001$ & .0002 \\
\hline Aortic homograft (worse) & .0002 & \\
\hline Complex left-sided heart disease & .003 & \\
\hline Younger age at Ross & .004 & \\
\hline Longer CPB time & .0004 & .009 \\
\hline \multicolumn{3}{|l|}{ LVOT } \\
\hline \multicolumn{3}{|l|}{ Diagnosis } \\
\hline Abnormal pulmonary valve & .0003 & .005 \\
\hline Original diagnosis $\mathrm{Al}$ & .03 & .006 \\
\hline \multicolumn{3}{|l|}{ Prior procedures } \\
\hline Aortic valve replacement & .0003 & .01 \\
\hline VSD repair & .05 & .04 \\
\hline Balloon valvotomy & .05 & \\
\hline \multicolumn{3}{|l|}{ Ross-related } \\
\hline Longer CPB time & .001 & .003 \\
\hline Older age at Ross & .01 & \\
\hline$\geq$ Moderate neo-Al at discharge & .04 & \\
\hline
\end{tabular}

and the proportion of patients with a $z$ score greater than 2 (9\%) had significantly decreased $(P=.0001$ for both).

\section{Discussion}

At midterm follow-up after the Ross procedure, interim mortality is rare. Left ventricular dysfunction is also uncommon, and there is normalization of left ventricular size in most patients. However, neoaortic insufficiency and right ventricle to pulmonary artery conduit obstruction are common postoperative sequelae, requiring reintervention in one quarter of patients.

Similar to other studies, our analysis confirms that the Ross procedure can be performed in a heterogeneous pediatric population, including infants and those with complex left-sided heart disease, with low early and midterm mortality. ${ }^{13-15}$ Given the low mortality rates associated with the Ross procedure, evaluation of outcomes in the literature has focused on the resolution of preoperative morbidities (eg, preoperative left ventricular dilation or dysfunction) and postoperative complications leading to reintervention.

Before the Ross procedure, there is often preexisting left ventricular dysfunction from volume and/or pressure overload, resulting in "mass-volume" mismatch. Similar to other studies of adult and pediatric patients undergoing the Ross procedure, our study demonstrated left ventricular remodeling over time, with a significant reduction in left ventricular end-diastolic dimension. ${ }^{14,16,19}$

After the Ross procedure, both RVOT and LVOT reinterventions have been shown to occur. Although the pul- 
monary autograft has the potential for growth after the Ross procedure, the homograft placed in the pulmonary position does not; therefore, RVOT reintervention can be expected in some patients. In our study, one quarter of patients required reintervention at midterm follow-up. Half of these were RVOT reinterventions, the majority of which were performed because of significant RVOT conduit stenosis, as seen in other studies. ${ }^{12-15}$ Ours is the first study to identify predictors of RVOT reintervention in the population who have undergone the Ross procedure. We found that smaller RVOT homograft size was the strongest predictor of RVOT reintervention. This is not surprising, because smaller homografts implanted in infants and children are not expected to grow with the child. A study of patients with congenital heart disease requiring surgery that included the placement of an RVOT homograft also found that young age and smaller homograft size predicted homograft reintervention. ${ }^{20}$ We also found that longer cardiopulmonary bypass time, likely a marker of disease complexity, predicted RVOT reintervention in multivariate analysis.

The proportion of patients requiring RVOT reintervention in our analysis (14\%) was higher than that found in other studies (5\%-10\%). ${ }^{13-15}$ However, our study included a larger number of neonates and infants (20\% of patients aged $<1$ year at the time of the Ross procedure). The majority of RVOT reinterventions in our study took place in the first 4 years after the Ross procedure. However, Kaplan-Meier analysis demonstrated a "late" phase ( $>4$ years after the Ross procedure) as well. Both early and late RVOT reinterventions have been documented in other studies. ${ }^{12,13,15,21}$ Longer follow-up is needed to evaluate whether further RVOT reintervention will occur in our population.

Although RVOT reintervention can be expected, especially in younger patients, we found that LVOT reintervention was equally as common, occurring in $14 \%$ of patients. Other studies have documented LVOT reintervention rates up to $10 \%$ at 10 -year follow-up. ${ }^{3,13,15}$ This is in comparison with children undergoing mechanical valve replacement, in whom LVOT reintervention has been shown to range from $10 \%$ to $20 \%$ at midterm follow-up. ${ }^{22-24}$

Similar to other studies, our study showed that the majority of LVOT reinterventions were performed for severe neoaortic insufficiency. ${ }^{3,13,15}$ In multivariate analysis, we found that the presence of native pulmonary valve abnormalities at the time of the Ross procedure was a predictor of LVOT reintervention. Early in our surgical experience, the Ross procedure was undertaken in patients with what were thought to be minor structural defects of the native pulmonary valve (eg, bicuspid or quadricuspid pulmonary valve or discrepancy in leaflet size) and no significant pulmonary regurgitation. However, all but 1 of these patients underwent LVOT reintervention, and this practice was abandoned. We now consider even subtle abnormalities of the native pulmonary valve a relative contraindication to the Ross procedure. A history of VSD repair before the Ross operation was also found to be a significant predictor of LVOT reintervention in multivariate analysis. At the time of prior VSD repair, sutures and patch material may be placed near the pulmonary valve annulus, with resultant scar formation. Because of this, care must be taken during pulmonary autograft excision, particularly along the posterior aspect. The sutures themselves, or difficult excision of the pulmonary autograft from surrounding scar tissue, may destabilize the pulmonary annulus, manifesting as neoaortic regurgitation when the pulmonary autograft is transitioned to the systemic circulation. In 1 of our patients who underwent VSD repair before the Ross procedure, a suture in the pulmonary valve annulus was noted at the time of the Ross procedure, with no pulmonary insufficiency. After the Ross procedure, progressive neoaortic insufficiency developed and the patient underwent early LVOT reintervention.

Factors impacting the structure and dimensions of the neoaortic root (original diagnosis of aortic insufficiency and aortic valve replacement before the Ross operation) were also significant predictors of LVOT reintervention. A prior study of pediatric patients by Elkins and colleagues ${ }^{3}$ also showed that those with a diagnosis of aortic insufficiency are at increased risk for LVOT reintervention after the Ross procedure. It is known that aortic insufficiency is associated with aortic root dilation, and it has been shown that a history of aortic root dilation before the Ross operation is a risk factor for LVOT reintervention. ${ }^{13,25}$ The relationship between the dimensions of the native aortic root and pulmonary autograft has been shown to be important in patients undergoing the Ross procedure; a mismatch in size may lead to pulmonary autograft failure. ${ }^{26,27}$ Long-standing aortic insufficiency or aortic valve replacement before the Ross procedure may impact the size of the aortic root, making a subsequent Ross operation more difficult. Finally, as with RVOT reintervention, we found that longer cardiopulmonary bypass time, likely a marker of disease complexity, predicted LVOT reintervention in multivariate analysis.

The time course of LVOT reintervention mirrored that of RVOT reintervention, with both an "early" and "late" phase. At the time of this analysis, 3 patients had undergone valve-sparing root replacement because of progressive dilation of the neoaortic root in the "late" postoperative period. Dilation of the neoaortic root out of proportion to somatic growth has been documented in patients who underwent the Ross procedure, as well as in other groups of patients in whom the pulmonary valve functions in the systemic circulation. ${ }^{16,17,28-30}$ This raises concern as to whether the incidence of LVOT reintervention will continue to increase as we follow patients into the second and third decades after the Ross procedure. 


\section{Limitations}

This is a study of a complex group of patients followed at a single center. The incidence, and predictors of, reintervention may not be applicable to all patients undergoing the Ross procedure. Selection bias within our population is unlikely, because only 5 patients were lost to follow-up. Finally, complete echocardiographic data were limited to patients followed at our institution or by outside cardiologists with data available on the most recent echocardiogram report.

\section{Conclusions}

The Ross procedure provides good palliation for the treatment of aortic valve disease in children and young adults with low mortality and normalization of left ventricular size at midterm follow-up. When the Ross procedure is performed in young patients, RVOT conduit reintervention can be expected. LVOT reintervention is equally as common as RVOT reintervention in this complex group of patients, occurring in $14 \%$ of patients. The natural history of the neoaortic valve and LVOT reintervention during the second to third decade of follow-up remains uncertain.

\section{References}

1. Ross DN. Replacement of the aortic and mitral valves with a pulmonary autograft. Lancet. 1967;2:956-8.

2. Elkins RC, Knott-Craig CJ, Ward KE, et al. Pulmonary autograft in children: realized growth potential. Ann Thorac Surg. 1994;57:1387-94.

3. Elkins RC, Lane MM, McCue C. Ross operation in children: late results. J Heart Valve Dis. 2001;10:736-41.

4. Gerosa G, McKay R, Ross DN. Replacement of the aortic valve root with a pulmonary autograft in children. Ann Thorac Surg. 1991;51: 424-9.

5. Kouchoukos NT, Davila-Roman VG, Spray TL, et al. Replacement of the aortic root with a pulmonary autograft in children and young adults with aortic valve disease. $N$ Engl J Med. 1994;330:1-6.

6. Reddy VM, Rajasinghe HA, McElhinney DB, et al. Extending the limits of the Ross procedure. Ann Thorac Surg. 1995;60:S600-3.

7. Reddy VM, Rajasinghe HA, Teitel DF, et al. Atrioventriculoplasty with the pulmonary autograft: the "Ross-Konno" procedure. J Thorac Cardiovasc Surg. 1996;111:158-67.

8. Starnes VA, Luciani GB, Wells WJ, et al. Aortic root replacement with the pulmonary autograft in children with complex left heart obstruction. Ann Thorac Surg. 1996;62:442-9.

9. Hvass U, Chatel D, Calliani J, et al. Relief of complex left ventricular outflow tract obstruction with pulmonary autografts. J Thorac Cardiovasc Surg. 1995;109:1019.

10. Marino BS, Wernovsky G, Rychik J, et al. Early results of the Ross procedure in simple and complex left heart disease. Circulation. 1999; 100(suppl II):II-162-6.

11. Ohye RG, Gomez CA, Ohye BJ, Goldberg CS, Bove EL. The Ross/ Konno procedure in neonates and infants: Intermediate-term survival and autograft function. Ann Thorac Surg. 2001;72:823-30.
12. Ward KE, Elkins RC, Overholt ED, et al. Evaluation of cryopreserved homografts in the right ventricular outflow tract after the Ross procedure: intermediate term follow-up. J Heart Valve Dis. 1997;6:130-3.

13. Luciani GB, Favaro A, Casali G, Santini F, Mazzucco A. Ross operation in the young: a ten-year experience. Ann Thorac Surg. 2005;80: 2271-7.

14. Hraska V, Krajci M, Haun C, et al. Ross and Ross-Konno procedure in children and adolescents: mid-term results. Eur J Cardiothorac Surg. 2004;25:742-7.

15. Hazekamp MG, Grotenhuis HB, Schoof PH, Rijlaarsdam MEB, Ottenkamp J, Dion RAE. Results of the Ross operation in a pediatric population. Eur J Cardiothorac Surg. 2005;27:975-9.

16. Tantengco MVT, Humes RA, Clapp SK, et al. Aortic root dilatation after the Ross procedure. Am J Cardiol. 1999;83:915-20.

17. Solowiejczyk DE, Bourlon F, Apfel H, et al. Serial echocardiographic measurements of the pulmonary autograft in the aortic valve position after the Ross operation in a pediatric population using normal pulmonary artery dimensions as the reference standard. Am J Cardiol. 2000;85:1119-23.

18. Spray TL. Technique of pulmonary autograft aortic valve replacement in children (The Ross Procedure). Semin Thorac Cardiovasc Surg Pediatr Card Surg Annu. 1998;1:165-78.

19. Nimaya K, Elkins RC, Knott-Craig CJ, Santangelo KL, Cannon MB, Lane MM. Normalization of left ventricular dimensions after Ross operation with aortic annular reduction. Ann Thorac Surg. 1999;68: $812-8$.

20. Tweddell JS, Pelech AN, Frommelt PC, et al. Factors affecting longevity of homograft valves used in right ventricular outflow tract reconstruction for congenital heart disease. Circulation. 2000;102: III130-5.

21. Carr-White GS, Kilner PJ, Hon JK, et al. Incidence, location, pathology, and significance of pulmonary homograft stenosis after the Ross operation. Circulation. 2001;18:116-20.

22. Turrentine MW, Ruzmetov M, Vijay P, et al. Biological versus mechanical aortic valve replacement in children. Ann Thorac Surg. 2001; 71:S356-60.

23. Alexiou C, McDonald A, Langley SM, et al. Aortic valve replacement in children: are mechanical prostheses a good option? Eur J Cardiothorac Surg. 2000;17:125-33.

24. Lupinetti FM, Duncan BW, Scifres AM, et al. Intermediate term results in pediatric aortic valve replacement. Ann Thorac Surg. 1999; 68:521-5.

25. Laudito A, Brook MM, Suleman S, et al. The Ross procedure in children and young adults: a word of caution. J Thorac Cardiovasc Surg. 2001;122:147-53.

26. Reddy VM, McElhinney DB, Phoon CK, Brook MM, Hanley FL. Geometric mismatch of pulmonary and aortic anuli in children undergoing the Ross procedure: implications for surgical management and autograft function. J Thorac Cardiovasc Surg. 1998;115:1255-62.

27. Klena JW, Shweiki E, Mahaffey HW, Woods EL, Benoit CH, Gilbert $\mathrm{CL}$. Annuloplasty and aortoplasty as modifications of the Ross procedure for the correction of geometric mismatch. $J$ Heart Valve Dis. 2000;9:195-9.

28. Hutter PA, Thomeer BJ, Jansen P, et al. Fate of the aortic root after arterial switch operation. Eur J Cardiothorac Surg. 2001;20:82-8.

29. Cohen MS, Marino BS, McElhinney DB, et al. Neo-aortic root dilation and valve regurgitation up to 21 years after staged reconstruction for hypoplastic left heart syndrome. J Am Coll Cardiol. 2003;42:533-40.

30. Puntel RA, Webber SA, Ettedgui JA, Tacy TA. Rapid enlargement of the neo-aortic root after the Ross procedure in children. Am J Cardiol. 1999;84:747-9. 